\title{
Spatio-temporal correlation between human and bovine schistosomiasis in China: insight from three national sampling surveys
}

\author{
Xiao-Hua Wuํ, Xian-Hong Wang ${ }^{1}$, Jürg Utzinger ${ }^{2}$, Kun Yang ${ }^{1}$, Thomas K. Kristensen ${ }^{3}$, \\ Robert Bergquist ${ }^{4}$, Gen-Ming Zhao ${ }^{5}$, Hui Dang ${ }^{1}$, Xiao-Nong Zhou ${ }^{1}$ \\ ${ }^{1}$ National Institute of Parasitic Diseases, Chinese Center for Disease Control and Prevention, Shanghai \\ 200025, People's Republic of China; ${ }^{2}$ Department of Public Health and Epidemiology, Swiss Tropical \\ Institute, P.O. Box, CH-4002 Basel, Switzerland; ${ }^{3}$ DBL - Centre for Health Research and Development, \\ Department of Veterinary Pathobiology, Faculty of Life Sciences, University of Copenhagen, Jaegersborg \\ Allé 1 D, DK-2920 Charlottenlund, Denmark; ${ }^{4}$ Ingerod 407, 45494 Brastad, Sweden; ${ }^{5}$ School of Public \\ Health, Fudan University, Shanghai 200032, People's Republic of China
}

\begin{abstract}
Insight into the spatial and temporal contamination of the environment by bovine faeces in China can provide important information on the significance of bovines in the transmission of human schistosomiasis. This insight will be useful for the new evidence-based strategy of the Chinese national schistosomiasis control programme. To enhance our understanding of the spatio-temporal relationship between the prevalence of human and bovine schistosomiasis, we performed correlation and regression analyses using data from three national sampling surveys on schistosomiasis, carried out in 1989, 1995 and 2004. In addition, we established a geographical information system and performed spatial analyses to identify the high-risk areas of the disease. We found that schistosomiasis is mainly concentrated in the marshlands along the Yangtze River. It was also noted that, although the human prevalence and force of transmission in highly endemic areas has been reduced since 1989, the relative importance of bovine schistosomiasis has increased. This is seen in a declining Spearman correlation coefficient between the infection prevalence in humans and in bovines over time (0.812 in 1989, 0.754 in 1995 and 0.376 in 2004). In parallel, the slope of the linear regression decreased from 0.395 in 1989 to 0.215 in 2004. Our data therefore suggest that future schistosomiasis control efforts in China should more vigorously address the important role of bovines in the transmission of human schistosomiasis, and to reduce the environmental contamination of Schistosoma japonicum eggs by bovines.
\end{abstract}

Keywords: Schistosomiasis, Schistosoma japonicum, national sampling survey, geographical information system, spatio-temporal analysis, epidemiology and control, bovine, China.

\section{Introduction}

Schistosomiasis is a water-borne parasitic disease with a complex life cycle, which explains the wide range of epidemiological and morbidity patterns (Fenwick, 2006; Gryseels et al., 2006). The causative

Corresponding author:

Xiao-Nong Zhou

National Institute of Parasitic Diseases

Chinese Center for Disease Control and Prevention

207 Rui Jin Er Road, Shanghai 200025, People's Republic of China

Tel. +86 216473 8058; Fax +862164332670

E-mail: ipdzhouxn@sh163.net agent of human schistosomiasis is a trematode of the genus Schistosoma. There are five schistosome species parasitizing humans; collectively over 200 million individuals are infected with an estimated 779 million at risk (Steinmann et al., 2006). China represents the largest endemic area of Schistosoma japonicum infection in the world (Ross et al., 1997). The achievements made in the control of schistosomiasis in China have reduced the number of human infections by more than $90 \%$ from the peak in the mid-1950s (Chen and Feng, 1999). The remaining endemic areas are found in the Yangtze River basin, 
around the great lakes of central China (Dongting Lake and Poyong Lake), and adjacent to small rivers in mountainous areas in south-western China, comprising 324 counties in seven provinces (Hao et al., 2005). At the beginning of the national schistosomiasis control programme in 1949, there were approximately $14,000 \mathrm{~km}^{2}$ of snail-infested areas with over 10 million people and an estimated 1.2 million bovines infected with $S$. japonicum in 12 provinces (Chen and Feng, 1999; Ross et al., 2001; Utzinger et al., 2005). At that time, schistosomiasis-attributable morbidity and mortality were high (Chen and Feng, 1999; Zhou et al., 2005b). Hence, schistosomiasis was a pressing public health problem holding back socio-economic development, which explains why the central government embarked on vigorous research and control activities early on. The results obtained through regular sampling surveys and the periodical surveillance system illustrate the progress made over the past half century (Utzinger et al., 2005; Zhou et al., 2005b).

To date, three national schistosomiasis sampling surveys have been carried out under the leadership of the Chinese Ministry of Health $(\mathrm{MoH})$; first in 1989, then in 1995 and most recently in 2004. The aim of these surveys was to determine the prevalence of S. japonicum in those parts of the country where transmission was still ongoing $(\mathrm{MoH}, 1993,1998$; Zhen, 1993), and to further adapt and fine-tune the national schistosomiasis control programme. The first sampling survey in 1989 found an impressive reduction in the number of infected people compared to the peak figure in the $1950 \mathrm{~s}$, but an estimated 1,638,103 individuals were still infected (Zhen, 1993; Chen, 1999). The second national sampling survey in 1995 reported an estimated 865,084 human infections (MoH, 1998), i.e. a 47\% reduction compared to the preceding survey. The latest survey in 2004 was designed as a nationwide cluster sample. Extrapolation to include all residents still living in endemic areas revealed a total of 726,112 human infections, a $16 \%$ reduction compared to the 1995 survey (Zhou et al., 2007a).

Despite substantial progress made over the past decades, transmission of $S$. japonicum persists in seven Chinese provinces; namely, Anhui, Hubei, Hunan, Jiangsu and Jiangxi in the lake region, and Sichuan and Yunnan in the mountainous region (Hao et al., 2005). Sustained control efforts are needed to consolidate the achievements made to date and stepped-up efforts may be necessary to further reduce the number of infections and force of transmission (Bian et al., 2004; Wang et al., 2005; Fenwick and Webster, 2006; Guo et al., 2006; Liang et al., 2006).

Transmission of schistosomiasis is closely related to environmental factors (Steinmann et al., 2006; Li et al., 2007; Liang et al., 2007). However, despite a number of recent studies that employed geographical information system (GIS) applications to define transmission factors that relate to control (Bergquist, 2001; Zhou et al., 2001, 2002, 2007b; Yang et al., 2005b; Chen et al., 2007), little is known about the geospatial correlation between human and animal schistosomiasis and their relative contribution to the transmission of the disease.

The purpose of this study was to enhance our understanding of the spatio-temporal relationship between the prevalence of human and bovine schistosomiasis with the overall aim to contribute to a renovation of the national schistosomiasis control strategy in China. To that end, the S. japonicum infection data retrieved from the three national sampling surveys mentioned above, both in humans and bovines (i.e. cattle and water buffaloes), have been subjected to correlation and regression analyses.

\section{Materials and methods}

\section{Parasitological data}

Prevalence data of $S$. japonicum infection in humans and bovines were obtained from the three national schistosomiasis sampling surveys carried out thus far (1989, 1995 and 2004). We established spatially-explicit databases by retrieving the human and bovine $S$. japonicum infection prevalence along with the geographical coordinates (longitude and latitude) of each village subjected to sampling. The 
National Institute of Parasitic Diseases, Chinese Center for Disease Control and Prevention in Shanghai (Zhou et al., 2005a) was entrusted by the $\mathrm{MoH}$ to design and manage the three surveys and to provide supervision throughout. The prevalence data were retrieved for the seven endemic provinces.

In the first and second national sampling surveys, human infections were detected directly by faecal examination using a miracidium hatching technique after egg concentration with a nylon tissue bag (Qiu and Xue, 1990). In the third survey, human infections were detected by a two-pronged diagnostic approach described elsewhere (Wu, 2002; Zhu, 2005). In brief, all inhabitants aged 5-65 years from the study villages were first screened serologically using an indirect enzyme-linked immunosorbent assay (ELISA) (for a review see Li, 1991). Second, a faecal sample taken from ELISA-positive individuals was subjected to the Kato-Katz technique (Katz et al., 1972; Yu et al., 1998) for the detection of $S$. japonicum eggs under a light microscope. In order to compare data obtained from the first two with the most recent survey, a village-specific correction factor was calculated, taking into account the false negative rate of the Kato-Katz technique (Zhou et al., 2007a). Bovine infections were diagnosed by faecal examination using the hatching technique (Qiu and Xue, 1990). The same diagnostic approach was employed throughout.

\section{Spatio-temporal analysis}

A GIS database, using ArcView GIS version 8.3 (ESRI, Redlands, CA, USA), was established and the prevalence of human and bovine schistosomiasis at the village level were analysed by the spatial analyst module of the ArcGIS software. Three vector layers were created per village, according to the three national sampling surveys, once the database had been linked to the GIS platform. The spatial prediction of the human and bovine schistosomiasis prevalence were explored, using an inverse distance weighted function. The spatio-temporal models of the human and bovine schistosomiasis prevalence were verified by a simple surface analysis approach.

\section{Statistical analysis}

Spearman correlation and regression analyses were used to explore the relationship between human and bovine infection with $S$. japonicum for each of the three national sampling surveys. The Spearman correlation coefficients between human and bovine schistosomiasis prevalence were calculated and the linear regression equations of the human to the bovine prevalence were produced, respectively, for the three surveys in SAS version 8.0 (SAS Institute, Inc., NC, USA).

\section{Results}

\section{Human and bovine schistosomiasis prevalence}

Table 1 summarises the parasitological data extracted from the three national sampling surveys. The first survey, conducted in 1989, covered 353 villages in the eight provinces that were endemic at that time; i.e., Anhui, Hubei, Hunan, Jiangsu, Jiangxi, Sichuan, Yunnan and Zhejiang. Six years later, the second survey was carried out in 364 villages, covering the same eight provinces. By the end of 1995, Zhejiang province, formerly with 54

Table 1. Parasitological data of the three national sampling survey of schistosomiasis in China.

\begin{tabular}{lcccr}
\hline $\begin{array}{l}\text { Year of national } \\
\text { sampling survey }\end{array}$ & $\begin{array}{l}\text { Number of } \\
\text { villages sampled }\end{array}$ & $\begin{array}{l}\text { Estimated number of } \\
\text { people infected }\end{array}$ & $\begin{array}{l}\text { Prevalence in } \\
\text { human }(\%)\end{array}$ & $\begin{array}{l}\text { Prevalence in } \\
\text { bovine }(\%)\end{array}$ \\
\hline 1989 & 353 & $1,638,103$ & 10.2 & 13.3 \\
1995 & 364 & 865,084 & 4.9 & 9.1 \\
2004 & 239 & 726,112 & 5.1 & 5.7 \\
\hline
\end{tabular}


endemic counties, passed the special evaluation on elimination of schistosomiasis and was declared to have reached the criteria for transmission interruption with the exception of small areas of residual snails (Wu et al., 2005). The third nationwide cluster sample survey, carried out in 2004, focussed on 239 villages, which covered the remaining seven endemic provinces (Zhou et al., 2007a).

\section{High-risk areas for schistosomiasis}

The results of the spatial analysis depicted in Figure 1 showed that the high-risk areas for schistosomiasis transmission are mainly distributed in the marshlands along the Yangtze River. The spatial dis- tribution of schistosomiasis in bovines is positively correlated to that in humans. However, both the distribution areas and prevalence rates according to stool examinations in cattle and water buffaloes tend to be significantly greater than those found when humans are examined. A comparison between the first survey, carried out in 1989, and the most recent one (2004) clearly shows that the prevalence and intensity of schistosomiasis infections have been reduced in humans and in bovines. Consequently, the spatial extent of the high-risk areas has been confined, except in the mountainous region in Sichuan province, where the prevalence in both humans and bovines were higher in 2004 compared to 1995 .
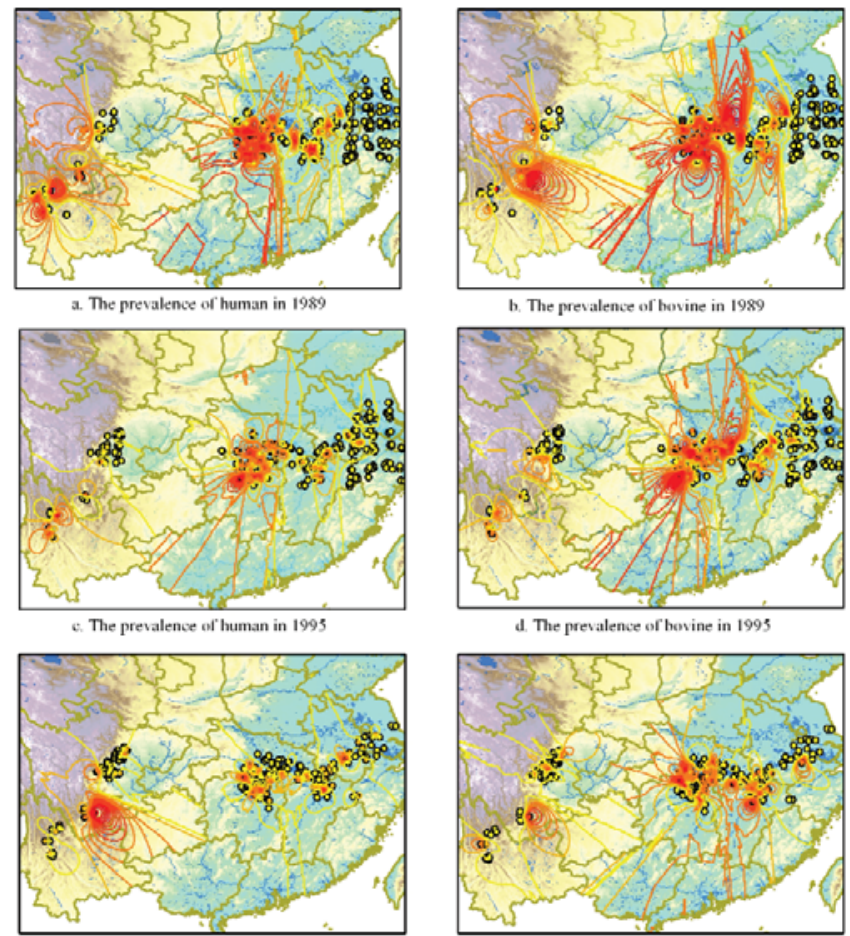

d. The prevalence of bovine in 1993

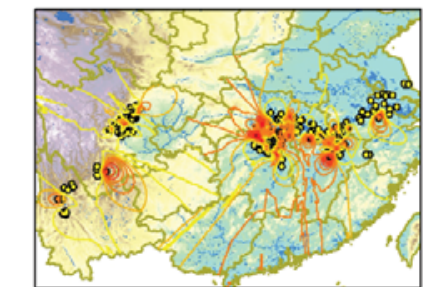

c. The prevalenes of human in 2004

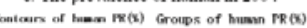

20.200 $0-2 \infty$

$204-5.00$

- $\operatorname{sor} 10.00$

- $20.04-20.00$

f. The prevalence of bovine in 2004

contours of bovine PR(x) Groups of bowine Pr(x)

$\sim \operatorname{sel}-\sin 00$

Niann - $-9 m$

1,360

and

Y.er 1000

N not now

$\sim 2001000$

- 200

- Lot Dor

- Not 10.00

- : Mar or

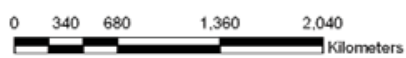

Fig. 1. The spatial distribution of the prevalence rates of human and bovine in the national sampling surveys on schistosomiasis carried out in 1989 (a,b), 1995 (c,d) and 2004 (e,f) in China. 
The significance of bovines for human schistosomiasis

A positive correlation was found between the prevalence of human infection and the prevalence of bovine infection for each of the three national sampling surveys, as shown in Figures 2a-2c. There was a remarkable reduction in the Spearman correlation coefficient over time. In the first survey in 1989, the Spearman correlation coefficient was 0.812 $(\mathrm{P}<0.001)$, in 1995 it was reduced to 0.754 $(\mathrm{P}<0.001)$ and, in 2004, the respective coefficient was $0.376(\mathrm{P}<0.001)$.

The results of the linear regression analysis are summarized in Table 2. A positive linear regression was found between the human and the bovine schistosomiasis prevalence. The regression equations for the three surveys were as follows: $y=0.395 x+2.698$ in the 1989 survey $(\mathrm{F}=127.9, \mathrm{P}<0.001) ; \mathrm{y}=0.318 \mathrm{x}$ +1.471 in the 1995 survey $(\mathrm{F}=136.4, \mathrm{P}<0.001)$; and $\mathrm{y}=0.215 \mathrm{x}+1.894$ in the 2004 survey $(\mathrm{F}=41.4$, $\mathrm{P}<0.001)$, where $\mathrm{y}$ is the infection prevalence in humans and $\mathrm{x}$ the prevalence in bovines.

\section{Discussion}

Application of GIS and remote sensing (RS) in human and veterinary medical sciences, particularly in human and veterinary parasitology, is rapidly advancing (Yang et al. 2005b; Hay et al., 2006; Rinaldi et al., 2006). GIS and RS are suitable tools for the creation of spatially-explicit databases, and the display of relevant data for health policy planning and discussion, guiding interventions and costeffective monitoring at a range of spatial scales (Tatem and Hay, 2004). Schistosomiasis japonica is an important zoonosis in China and The Philippines, whose distribution, prevalence and intensity of infection are particularly sensitive to the climatic and geographical environment (Yang et al., 2005a; Zhou et al., 2005b, 2007b; Li et al., 2007; Liang et al., 2007).


Fig. 2. Relationship between human and bovine prevalence of $S$. japonicum according to national survey data in 1989 (a), 1995 (b) and 2004 (c).

Table 2. Results of linear regression analysis between the prevalence in human and bovine of the three national sampling surveys of schistosomiasis in China.

\begin{tabular}{lccccrr}
\hline $\begin{array}{l}\text { Year of national } \\
\text { sampling survey }\end{array}$ & Slope & Intercept & $\begin{array}{c}\text { Standard error of } \\
\text { slope }\end{array}$ & R-square & F value & P value \\
\hline 1989 & 0.395 & 2.698 & 0.035 & 0.279 & 127.9 & $<0.001$ \\
1995 & 0.318 & 1.471 & 0.027 & 0.275 & 136.4 & $<0.001$ \\
2004 & 0.215 & 1.894 & 0.033 & 0.150 & 41.4 & $<0.001$ \\
\hline
\end{tabular}


The spatial analysis carried forward in the current paper confirms that the prevalence of human and bovine schistosomiasis in China has been reduced considerably since 1989 when the first national sampling survey was carried out and, although the size of the transmission areas has also been reduced, highrisk areas remain in the marshlands along the Yangtze River and around Dongting Lake and Poyang Lake, which are connected to a dense network of rivers. However, in the mountainous regions of Sichuan province, both human and bovine prevalence increased in 2004 when compared to 1995, and there is concern about the re-emergence of schistosomiasis there (Liang et al., 2006). According to the 1989 survey, the estimated number of infected people was around 1.6 million, and hence the human prevalence rate in schistosome-endemic areas was $10.2 \%$. The corresponding bovine prevalence rate was $13.3 \%$. In some areas, the prevalence rate of humans reached levels as high as $49 \%$, while bovine prevalence rates in excess of $95 \%$ were found $(\mathrm{MoH}, 1993)$. Six years later, the human infection rate in schistosome-endemic areas decreased to $4.9 \%$, as revealed by the second national sampling survey in 1995 (a reduction of $52.1 \%$ ). Over the same period, the average bovine infection rate decreased from $13.3 \%$ to $9.1 \%$, which translates to a reduction of $31.8 \%$. In $1995,865,084$ people were estimated to be infected with $S$. japonicum (MoH, 1998). The third national sampling survey in 2004 estimated the number of human infections at 726,112 (Zhou et al., 2007a). It is important to note that this figure was arrived at using a correction factor for calculating the total number of infections due to the lack of sensitivity of the Kato-Katz technique (Zhou et al., 2007a). Interestingly, the human prevalence rate in the areas where transmission control had not been achieved increased slightly from $4.9 \%$ in 1995 to $5.1 \%$, an increase of $3.9 \%$. Several factors have been suggested as underlying causes, such as the unusually severe floods that occurred in 1998 (Zhou et al., 2002), major demographic and ecological transformations due to waterresource developments and the anti-flooding policy (Xu et al., 2000; Chen, 2002; Jiang et al., 2002;
Zheng et al., 2002; Li et al., 2007), the potential impact of climate change (Zhou et al., 2004b; Yang et al., 2005a), health sector reforms (Jiang et al., 2002; Bian et al., 2004), and the termination of the World Bank Loan Project (WBLP) on schistosomiasis control with insufficient attention given to further consolidate achievements made in the 1990s (Yuan et al., 2000; Zhou et al., 2004a).

$S$. japonicum differs from other schistosome species in that more than 40 mammal species can act as reservoir hosts. At least ten of these animal species play some role in the transmission of the disease in China (Chen, 1993; WHO, 1993). Particularly in the lake region, domestic animals are left to graze freely, whereas water buffaloes are mostly kept in the marshlands and graze during the transmission season in the contaminated areas where they often defecate directly onto the snail habitats (Wang et al., 1989; Zheng et al., 1990). The environmental contamination is still largely due to water buffaloes, whose high faecal output is generally laden with schistosome eggs. Previous research has shown that in some settings, water buffaloes contribute more than $90 \%$ of the environmental contamination of schistosome eggs (Wang et al., 2005). It is noteworthy that the average stool weight of cattle per day, estimated at $25 \mathrm{~kg}$, is 100 times that of humans (approximately $250 \mathrm{~g}$ ), while the water buffaloes produce $50-60 \mathrm{~kg}$ of stool daily (Guo et al., 2001; Ross et al., 2001).

As showed in Figure 1, the spatial distribution of bovine schistosomiasis coincides with the distribution of human infections, but the prevalence tends to be much higher with regard to the former than the latter. A positive correlation was shown between the human and the bovine prevalence rates in all three sampling surveys, but the Spearman correlation coefficient decreased over time, i.e. 0.812 in 1989, 0.754 in 1995 and 0.376 in $2004(\mathrm{P}<0.001$ for pair wise comparisons). Meanwhile, the infection rate of livestock reached levels of up to $66.7 \%$ in the marshlands around the Dongting Lake, while it was $21.5 \%$ for cattle infection in the mountainous areas in Sichuan province in the 2004 survey.

Since the beginning of the WBLP in 1992, schisto- 
somiasis control activities in most endemic areas of China were mainly based on the regular administration of praziquantel to at-risk populations (Jiang et al., 1996; Zhou et al., 2005b). Concurrent animal chemotherapy in high-risk areas is generally attempted but has only achieved limited coverage $(50 \%)$ and less success. This is not only due to the higher bovine re-infection rate, but also due to difficulties in accomplishing the goal of effective treatment (Guo et al., 2001). The results presented here suggest that current measures for control of cattle and water buffalo infection constitute a weak link in the national schistosomiasis control programme. This is underlined by the positive correlation, and linear regression, between the infection prevalence in humans and bovines seen in all three national sampling surveys. However, as depicted in Figures 2a-2c, there is a tendency of reduction both in the Spearman correlation coefficients and in the slope of the linear regression (from 0.395 in 1989 to 0.215 in 2004). The fact that bovines play a major role in the transmission of human schistosomiasis in China is supported by mathematical modelling (Williams et al., 2002), as well as by a recently completed intervention study where either humans alone or humans plus buffaloes were treated with praziquantel (Guo et al., 2006). The implications for schistosomiasis control, including development of a bovine vaccine, have been discussed (Guo et al., 2006; McManus and Dalton, 2006). The evidence linking the contribution to transmission by domestic animals points to the looming threat of decreasing returns from human chemotherapy, as the higher the prevalence among domestic animals the higher the risk of infection for humans.

Contamination by S. japonicum eggs from domestic animals of pastures frequented by farmers and humans in general seems to be the key factor for schistosomiasis japonica to currently resist control even giving the impression of re-emergency in some places. This situation is potentially hazardous for the continued success of the national control programme, and hence, we recommend that the strategy for high-risk areas should be modified to spearhead a reduction of schistosomiasis transmission. A specific approach emphasizing elimination of the source of infection by targeting the egg contamination of snail habitats would be a useful addition to the integrated control strategy now used.

\section{Conclusions}

If strong efforts are not undertaken to control schistosomiasis in the bovine population in China, the chemotherapy-based control strategy runs the risk of becoming considerably less effective in the future. We propose a four-pronged approach to accomplish the objective of interrupting egg contamination of the environment, consisting of:

(i) increasing the mechanization of agriculture;

(ii) discouraging marshland pastures and introduction of fenced cattle farming (as is already required for pigs);

(iii) construction of latrines in homes; and

(iv) provision of latrines in the field for 'night-soil' collection for mobile populations such as fishermen.

In our opinion, near complete elimination of S. japonicum contamination is indeed possible if such a control strategy could be deployed along with other control activities.

\section{Acknowledgements}

Our sincere thanks go to the many people and organizations providing assistance in one way or the other during the three national sampling surveys for schistosomiasis in China. This includes all staff from the eight provincial institutions and counties involved in the surveys. Financial support for the field activities was granted by the $\mathrm{MoH}$ and the Department of Health in the eight respective provinces. This work received support from the National Natural Science Foundation of China (grant no. 30590373), from the UNICEF/UNDP/World Bank/WHO Special Programme for Research and Training in Tropical Diseases (TDR) (grant no. A30298), and from the Ministry of Science and Technology (grant no. 2004BA718B12). J. Utzinger acknowledges financial support from the Swiss National Science Foundation (project no. PPOOB-102883). 


\section{References}

Bergquist NR, 2001. Vector-borne parasitic diseases: new trends in data collection and risk assessment. Acta Trop 79, 13-20.

Bian Y, Sun Q, Zhao Z, Blas E, 2004. Market reform: a challenge to public health - the case of schistosomiasis control in China. Int J Health Plann Manage 19, S79-94.

Chen MG, 1993. Schistosoma japonicum and S. japonicumlike infections: epidemiology, clinical and pathological aspects. In: Jordan P, Webbe G, Sturrock RF (Eds.), Human Schistosomiasis, CAB International, Wallingford, United Kingdom, pp. 237-270.

Chen MG, 1999. Progress in schistosomiasis control in China. Chin Med J 112, 930-933.

Chen MG, Feng Z, 1999. Schistosomiasis control in China. Parasitol Int 48, 11-19.

Chen XY, 2002. The challenges and strategies in schistosomiasis control program in China. Acta Trop 82, 279-282.

Chen Z, Zhou XN, Yang K, Wang XH, Yao ZQ, Wang TP, Yang GJ, Yang YJ, Zhang SQ, Wang J, Jia TW, Wu XH, 2007. Strategy formulation for schistosomiasis japonica control in different environmental settings supported by spatial analysis: a case study from China. Geospatial Health 1, 223-231.

Fenwick A, 2006. Waterborne infectious diseases - could they be consigned to history? Science 313, 1077-1081.

Fenwick A, Webster JP, 2006. Schistosomiasis: challenges for control, treatment and drug resistance. Curr Opin Infect Dis $19,577-582$.

Gryseels B, Polman K, Clerinx J, Kestens L, 2006. Human schistosomiasis. Lancet 368, 1106-1118.

Guo JG, Li YS, Gray D, Ning A, Hu GH, Chen HG, Davis GM, Sleigh AC, Feng Z, McManus DP, Williams GM, 2006. A drug-based intervention study on the importance of buffaloes for human Schistosoma japonicum infection around Poyang Lake, People's Republic of China. Am J Trop Med Hyg 74, 335-341.

Guo JG, Ross AGP, Lin DD, Williams GM, Chen HG, Li Y, Davis GM, Feng Z, McManus DP, Sleigh AC, 2001. A baseline study on the importance of bovines for human Schistosoma japonicum infection around Poyang Lake, China. Am J Trop Med Hyg 65, 272-278.

Hao Y, Wu XH, Xia G, Zheng H, Guo JG, Wang LY, Zhou
XN, 2005. Schistosomiasis situation in People's Republic of China in 2004. Chin J Schisto Cont 17, 401-404.

Hay SI, Tatem AJ, Graham AJ, Goetz SJ, Rogers DJ, 2006. Global environmental data for mapping infectious disease distribution. Adv Parasitol 62, 37-77.

Jiang Q, Zhang S, Yuan H, Liu Z, Zhao G, Brinkmann U, 1996. The effect of a combined approach to schistosomiasis control on the transmission of Schistosoma japonicum in Xingzi of Poyang Lake area, China. Southeast Asian J Trop Med Public Health 27, 535-541.

Jiang QW, Wang LY, Guo JG, Chen MG, Zhou XN, Engels D, 2002. Morbidity control of schistosomiasis in China. Acta Trop 82, 115-125.

Katz N, Chaves A, Pellegrino J, 1972. A simple device for quantitative stool thick-smear technique in schistosomiasis mansoni. Rev Inst Med Trop Sao Paulo 14, 397-400.

Li Y, 1991. Advance of the study on immunodiagnosis of schistosomiasis. In: Li Y (Ed.), Immunology and Immunodiagnosis of Parasitic Diseases. Jiangsu Science Technology Publishing House, Nanjing, pp. 210-234.

Li YS, Raso G, Zhao ZY, He YK, Ellis MK, McManus DP, 2007. Large water management projects and schistosomiasis control, Dongting Lake region, China. Emerg Infect Dis 13, 973-979.

Liang S, Seto EYW, Remais JV, Zhong B, Yang CH, Hubbard A, Davis GM, Gu XG, Qiu DC, Spear RC, 2007. Environmental effects on parasitic disease transmission exemplified by schistosomiasis in western China. Proc Natl Acad Sci USA 104, 7110-7115.

Liang S, Yang CH, Zhong B, Qiu DC, 2006. Re-emerging schistosomiasis in hilly and mountainous areas of Sichuan, China. Bull World Health Organ 84, 139-144.

McManus DP, Dalton JP, 2006. Vaccines against the zoonotic trematodes Schistosoma japonicum, Fasciola hepatica and Fasciola gigantica. Parasitology 133, S43-61.

$\mathrm{MoH}, 1993$. Epidemiological situation of schistosomiasis in China - results from a nation-wide sampling survey in 1989. Chengdu Technology University Press, Chengdu, People's Republic of China.

$\mathrm{MoH}, 1998$. Epidemic status of schistosomiasis in China - a nationwide sampling survey in 1995. Nanjing University Press, Nanjing, People's Republic of China.

Qiu LZ, Xue HC, 1990. Experimental diagnosis. In: Mao SP (Ed.), Schistosome Biology and Control of Schistosomiasis. 
Publishing House for People's Health, Beijing, pp. 448-527. Rinaldi L, Musella V, Biggeri A, Cringoli G, 2006. New insights into the application of geographical information systems and remote sensing in veterinary parasitology. Geospatial Health 1, 33-47.

Ross AGP, Li YS, Sleigh AC, McManus DP, 1997. Schistosomiasis control in the People's Republic of China. Parasitol Today 13, 152-155.

Ross AGP, Sleigh AC, Li YS, Davis GM, Williams GM, Jiang Z, Feng Z, McManus DP, 2001. Schistosomiasis in the People's Republic of China: prospects and challenges for the 21st century. Clin Microbiol Rev 14, 270-295.

Steinmann P, Keiser J, Bos R, Tanner M, Utzinger J, 2006. Schistosomiasis and water resources development: systematic review, meta-analysis, and estimates of people at risk. Lancet Infect Dis 6, 411-425.

Tatem AJ, Hay SI, 2004. Measuring urbanization pattern and extent for malaria research: a review of remote sensing approaches. J Urban Health 81, 363-376.

Utzinger J, Zhou XN, Chen MG, Bergquist R, 2005. Conquering schistosomiasis in China: the long march. Acta Trop 96, 69-96.

Wang TP, Cui XM, Li TS, Lu GY, Guan QZ, Chen DL, Zhou L, Qing XY, 1989. The importance of domestic animals in schistosomiasis transmission in Beilang Lake, Tonglin county. Chin J Schisto Cont 1, 39-40.

Wang TP, Johansen MV, Zhang SQ, Wang FF, Wu WD, Zhang GH, Pan XP, Ju Y, Ørnbjerg N, 2005. Transmission of Schistosoma japonicum by humans and domestic animals in the Yangtze River valley, Anhui province, China. Acta Trop 96, 198-204.

WHO, 1993. The control of schistosomiasis. Second report of the WHO Expert Committee. WHO Tech Rep Ser 830, 1-86. Williams GM, Sleigh AC, Li YS, Feng Z, Davis GM, Chen H, Ross AGP, Bergquist R, McManus DP, 2002. Mathematical modelling of schistosomiasis japonica: comparison of control strategies in the People's Republic of China. Acta Trop $82,253-262$.

Wu GL, 2002. A historical perspective on the immunodiagnosis of schistosomiasis in China. Acta Trop 82, 193-198.

Wu XH, Chen MG, Zheng J, 2005. Surveillance of schistosomiasis in five provinces of China which have reached the national criteria for elimination of the disease. Acta Trop 96, 276-281.
Xu XJ, Wei FH, Yang XX, Dai YH, Yu GY, Chen LY, Su ZM, 2000. Possible effects of the Three Gorges dam on the transmission of Schistosoma japonicum on the Jiang Han plain, China. Ann Trop Med Parasitol 94, 333-341.

Yang GJ, Vounatsou P, Zhou XN, Tanner M, Utzinger J, 2005a. A potential impact of climate change and water resource development on the transmission of Schistosoma japonicum in China. Parassitologia 47, 127-134.

Yang GJ, Vounatsou P, Zhou XN, Utzinger J, Tanner M, 2005b. A review of geographic information system and remote sensing with applications to the epidemiology and control of schistosomiasis in China. Acta Trop 96, 117-129.

Yu JM, de Vlas SJ, Yuan HC, Gryseels B, 1998. Variations in fecal Schistosoma japonicum egg counts. Am J Trop Med Hyg 59, 370-375.

Yuan HC, Guo JG, Bergquist R, Tanner M, Chen XY, Wang HZ, 2000. The 1992-1999 World Bank Schistosomiasis Research Initiative in China: outcome and perspectives. Parasitol Int 49, 195-207.

Zhen J, 1993. A brief introduction to a nation-wide sampling survey on schistosomiasis. Chin Med J 106, 569-575.

Zheng J, Gu XG, Xu YL, Ge JH, Yang XX, He CH, Tang C, Cai KP, Jiang QW, Liang YS, Wang TP, Xu XJ, Zhong JH, Yuan HC, Zhou XN, 2002. Relationship between the transmission of schistosomiasis japonica and the construction of the Three Gorge Reservoir. Acta Trop 82, 147-156.

Zheng J, Qian K, Yao BY, Zhu HQ, Chen ZH, Zhang R, 1990. Study on the distribution pattern of schistosomiasis infection sources in mountainous regions. Chin J Schisto Cont 2, 24-26.

Zhou XN, Chen JX, Chen MG, Bergquist R, 2005a. The National Institute of Parasitic Diseases, Chinese Center for Disease Control and Prevention: a new administrative structure for schistosomiasis control. Acta Trop 96, 296-302.

Zhou XN, Guo JG, Wu XH, Jiang QW, Zheng J, Dang H, Wang XH, Xu J, Zhu HQ, Wu GL, Li YS, Xu XJ, Chen HG, Wang TP, Zhu YC, Qiu DC, Dong XQ, Zhao GM, Zhang SJ, Zhao NQ, Xia G, Wang LY, Zhang SQ, Lin DD, Chen MG, Hao Y, 2007a. Epidemiology of schistosomiasis in the People's Republic of China, 2004. Emerg Infect Dis $13,1470-1476$.

Zhou XN, Leonardo LR, Acosta LP, Johansen MV, Willingham AL, Olveda RM, 2007b. Schistosomiasis and other zoonoses in Southeast Asia - meeting report the 6th 
regional network for Asian schistosomiasis. Southeast Asian J Trop Med Public Health 38, 406-409.

Zhou XN, Lin DD, Yang HM, Chen HG, Sun LP, Yang GJ, Hong QB, Brown L, Malone, JB, 2002. Use of Landsat TM satellite surveillance data to measure the impact of the 1998 flood on snail intermediate host dispersal in the lower Yangtze River Basin. Acta Trop 82, 199-205.

Zhou XN, Malone JB, Kristensen TK, Bergquist NR, 2001. Application of geographic information systems and remote sensing to schistosomiasis control in China. Acta Trop 79, 97-106.

Zhou XN, Wang LY, Chen MG, Wu XH, Jiang QW, Chen
XY, Zheng J, Utzinger J, 2005b. The public health significance and control of schistosomiasis in China - then and now. Acta Trop 96, 97-105.

Zhou XN, Wang TP, Wang LY, Guo JG, Yu Q, Xu J, Wang RB, Chen Z, Jia TW, 2004a. The current status of schistosomiasis epidemics in China. Chin J Epidemiol 25, 555-558. Zhou XN, Yang K, Hong QB, Sun LP, Yang GJ, Liang YS, Huang YX, 2004b. Prediction of the impact of climate warming on transmission of schistosomiasis in China. Chin J Parasitol Parasit Dis 22, 262-265.

Zhu YC, 2005. Immunodiagnosis and its role in schistosomiasis control in China: a review. Acta Trop 96, 130-136. 